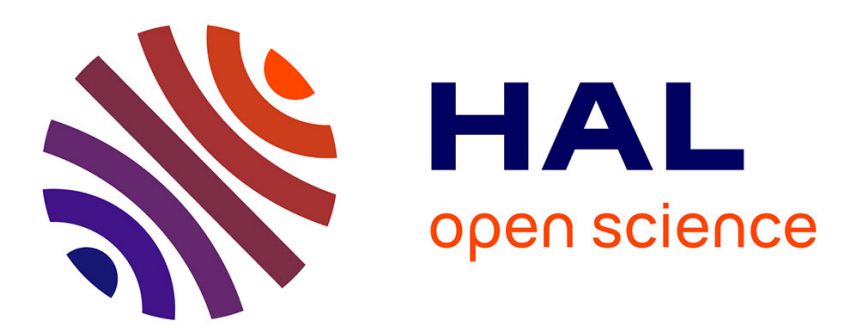

\title{
Multimodal Outcome at 7 Years of Age after Neonatal Arterial Ischemic Stroke
}

Stéphane Chabrier, Emeline Peyric, Laure Drutel, Johanna Deron, Manoelle

Kossorotoff, Mickaël Dinomais, Leila Lazaro, Jérémie Lefranc, Guillaume

Thébault, Gérard Dray, et al.

\section{To cite this version:}

Stéphane Chabrier, Emeline Peyric, Laure Drutel, Johanna Deron, Manoelle Kossorotoff, et al.. Multimodal Outcome at 7 Years of Age after Neonatal Arterial Ischemic Stroke. The Journal of Pediatrics, 2016, 172, pp.156-161.e3. 10.1016/j.jpeds.2016.01.069 . hal-02099375

\section{HAL Id: hal-02099375 \\ https://hal.science/hal-02099375}

Submitted on 8 Jun 2021

HAL is a multi-disciplinary open access archive for the deposit and dissemination of scientific research documents, whether they are published or not. The documents may come from teaching and research institutions in France or abroad, or from public or private research centers.
L'archive ouverte pluridisciplinaire HAL, est destinée au dépôt et à la diffusion de documents scientifiques de niveau recherche, publiés ou non, émanant des établissements d'enseignement et de recherche français ou étrangers, des laboratoires publics ou privés. 


\title{
Multimodal Outcome at 7 Years of Age after Neonatal Arterial Ischemic Stroke
}

\author{
Stéphane Chabrier, MD ${ }^{1,2}$, Emeline Peyric, MSc ${ }^{1}$, Laure Drutel, $\mathrm{MSc}^{1}$, Johanna Deron, MSc ${ }^{1}$, \\ Manoëlle Kossorotoff, MD, $\mathrm{PhD}^{3,4}$, Mickaël Dinomais, MD, $\mathrm{PhD}^{5,6}$, Leila Lazaro, $\mathrm{MD}^{7}$, Jérémie Lefranc, $\mathrm{MD}^{8}$, \\ Guillaume Thébault, $\mathrm{MSc}^{2,9}$, Gérard Dray, $\mathrm{PhD}^{10}$, Joel Fluss, $\mathrm{MD}^{11}$, Cyrille Renaud, $\mathrm{PhD}^{1,2}$, and \\ Sylvie Nguyen The Tich, MD, $\mathrm{PhD}^{6,12}$, on behalf of the \\ Accident Vasculaire Cérébral du nouveau-né (AVCnn; [Neonatal Stroke]) Study Group*
}

\begin{abstract}
Objectives To evaluate the epileptic, academic, and developmental status at age 7 years in a large population of term-born children who sustained neonatal arterial ischemic stroke (NAIS), and to assess the co-occurrence of these outcomes.
\end{abstract}

Study design A cohort study including 100 term newborns with NAIS was designed. Two infants died during the neonatal period, 13 families were lost to follow-up, and 5 families declined to participate in this evaluation. Thus, 80 families completed the 7-year clinical assessment. Epileptic status, schooling, motor abilities, global intellectual functioning, spoken language, and parental opinions were recorded. Principal component analysis was applied.

Results Rates of impaired language, cerebral palsy, low academic skills, active epilepsy, and global intellectual deficiency were $49 \%, 32 \%, 28 \%, 11 \%$, and $8 \%$, respectively. All were highly correlated. Eventually, $59 \%$ of children were affected by at least 1 of the aforementioned conditions. In $30 \%$ of cases, the viewpoints of health practitioners and parents did not match.

Conclusion The prevalence of severe disabilities at 7 years after NAIS is low, but most children exhibit some impairment in developmental profile. (J Pediatr 2016;172:156-61).

Trial registration ClinicalTrials.gov (NCT02511249), Programme Hospitalier de Recherche Clinique Régional (0308052), Programme Hospitalier de Recherche Clinique Interrégional (1008026), and EudraCT (2010-A00329-30).

lthough perinatal ischemic stroke (PIS) is common, ${ }^{1,2}$ its long-term outcomes remain poorly understood. Two main biases limit the accuracy of most studies: heterogeneity/small size of the sample and too short or informal follow-up.

The first consideration is that PIS encompasses several disease states that differ in pathophysiology, timing of occurrence, and clinical presentation. ${ }^{1,3}$ Thus, it is not surprising that outcome depends primarily on the subtype of stroke. For example, nearly all children who suffer an arterial presumed PIS or a fetal periventricular venous infarction have motor impairment, compared with one-third of those with a neonatal arterial ischemic stroke (NAIS; ie, arterial PIS with clinical manifestations before the 29th postnatal day).

Age at evaluation also plays a major role. Indeed, even though the original lesion in NAIS is focal and nonprogressive, its consequences within the maturing brain as a whole are amplified over time, compounded by environmental impacts, and thus affecting all dynamic and multidimensional fields of development. ${ }^{4}$

The AVCnn (Accident Vasculaire Cérébral du nouveau-né [neonatal stroke]) Study gives us the opportunity to monitor a cohort of term-born children having

\begin{tabular}{|c|c|c|c|}
\hline AVCnn & $\begin{array}{l}\text { Accident Vasculaire Cérébral du } \\
\text { nouveau-né (neonatal stroke) }\end{array}$ & $\begin{array}{l}\text { PCA } \\
\text { PIS }\end{array}$ & $\begin{array}{l}\text { Principal component analysis } \\
\text { Perinatal ischemic stroke }\end{array}$ \\
\hline BFMF & Bimanual Fine Motor Function & PRI & Perceptual Reasoning Index \\
\hline $\mathrm{CP}$ & Cerebral palsy & PSI & Processing Speed Index \\
\hline FSIQ & Full-scale IQ & $\mathrm{VCl}$ & Verbal Comprehension Index \\
\hline GMFCS & $\begin{array}{l}\text { Gross Motor Function } \\
\text { Classification Scale }\end{array}$ & WISC-IV & $\begin{array}{l}\text { Wechsler Intelligence Scale for } \\
\text { Children-Fourth Edition }\end{array}$ \\
\hline NAIS & Neonatal arterial ischemic stroke & WMI & Working Memory Index \\
\hline
\end{tabular}

From the ${ }^{1}$ Centre Hospitalier Universitaire (CHU) SaintÉtienne, French Center for Pediatric Stroke/Pediatric Physical and Rehabilitation Medicine Department and Institut national de la santé et de la recherche médicale Centre d'investigation Clinique (INSERM CIC) 1408; ${ }^{2}$ INSERM and University of Lyon, Dysfonction vasculaire et hémostase (DVH) Team-Unité mixte de recherche (UMR) 1090 Sainbiose, Saint-Étienne, France;

${ }^{3}$ Assistance publique-Hopitaux de Paris (AP-HP), French
Sent ${ }^{3}$ Assistance publique-Hôpitaux de Paris (AP-HP),
Center for Pediatric Stroke/Pediatric Neurology Department, University Hospital Necker-Enfants Malades; ${ }^{4}$ INSERM and University of Paris 5 , Thérapeutiques innovantes en hémostase-UMRS1140 Paris, France; ${ }^{5}$ Physical and Rehabilitation Medicine Department, L'Université Nantes Angers le Mans (LUNAM) CHU Angers; ' 6 Laboratoire Angevin de Recherche en Ingénierie des systèmes (LARIS)-EA7315, LUNAM Université Angers, Angers, France; ${ }^{7}$ Pediatrics Department, Centre hospitalier (CH) Côte-Basque, Bayonne, France; ${ }^{8}$ Pediatrics and Medical Genetics Deparment, CHU Brest, Brest, France; ${ }^{9}$ Dynamique des capacités humaines et des conduites de santé -Laboratory Epsylon EA4556, Université Montpellier 3, Montpellier, France; ${ }^{10}$ Mines Alès, Laboratoire de génie informatique et d'ingénierie de production (LG2IP), Nîmes, France; ${ }^{11}$ Pediatric Neurology, Pediatric Subspecialties Service, Children's Hospital, Geneva University Hospital, Geneva, Switzerland; and ${ }^{12}$ Neuropediatrics Department, LUNAM CHU Angers, Angers, France

*List of additional AVCnn Study Group members is available in the Appendix (available at www.jpeds.com). Funded by Ministère de la santé et des solidarités (0308052 and 1008026), Centre hospitalier universitaire de Saint-Étienne (085), Fondation motrice, Fondation Garches, Association des paralysés de France, and Fondation de France. The authors declare no conflicts of interest. 
suffered an NAIS. Here we present the clinical evaluation of these children at age 7 years. As observed in multiple situations with early brain insult, our hypothesis was that developmental disabilities co-occur, along with epilepsy. ${ }^{2,5-12}$

\section{Methods}

The objective of the AVCnn study was to better delineate the risk factors, clinical and imaging presentation, mechanisms, and outcomes of NAIS, while avoiding the confounders described above. The study was conducted in accordance with international ethical standards and the Declaration of Helsinki. The current evaluation at age 7 years was approved by the Regional Ethics Committee in May 2010. Informed consent was obtained from each participant. The reporting of results follows the general guidelines for observational studies. ${ }^{13}$

The study design is a birth closed-cohort study. ${ }^{14}$ NAIS was defined as "a focal disruption of arterial cerebral blood flow, causing neurological symptoms and confirmed by neuroimaging (computed tomography and/or magnetic resonance imaging, centrally reviewed for all cases) after birth and before the 29th postnatal day." ${ }^{3}$ A total of 100 newborns (62 boys) were enrolled between November 2003 and October 2006 in 39 units distributed throughout France. To eliminate the consequences of prematurity, only term newborns were included. Patients with fetal stroke, cerebral sinovenous thrombosis, presumed PIS, or diffuse ischemic lesions were excluded. Clinical and imaging neonatal findings and outcomes at ages 2 and 3.5 years have been reported previously. ${ }^{14-16}$

\section{Assessment at age 7 Years}

Regular contacts with the families and local physicians have been maintained since enrollment. Formal encounters took place during the systematic visits at ages 1,2 , and 3.5 years. Annual newsletters were sent to keep the families informed of the results of the ongoing study and the planned evaluations.

In 2010, families were asked via mailed letters to participate in the 7-year assessment. Those who accepted were contacted by phone by the study coordinators in the months before the child's seventh birthday and invited to attend a presentation on the current project. The encounter took place over an entire day in a medical setting close to the family residence. The evaluation team included a neuropsychologist, a speech therapist, and either a pediatric neurologist or a pediatric physical and rehabilitation medicine practitioner. All expenses were supported by the AVCnn study.

Three main categories of data were recorded: (1) history since the neonatal period; (2) developmental profile; and (3) parent opinions regarding the child's present function. The following items were documented: (1) medical history, notably the occurrence of seizures; (2) schooling; (3) gross and fine motor abilities; (4) global intellectual functioning; (5) spoken language; and (6) a single closed question to the family: "Do you consider that your child suffers any sequelae of his/her neonatal event?"

\section{Variables and Endpoints}

Epilepsy was defined as the occurrence of 2 or more afebrile unprovoked seizures after the neonatal period or, in the case of a single afebrile unprovoked seizure, the initiation of antiepileptic treatment. Epilepsy and seizures were classified according to the current International League Against Epilepsy terminology and classification scheme. ${ }^{17}$ Seizurefree at age 7 years was defined as the absence of seizures and treatment for $>1$ year. Otherwise, epilepsy was classified as active.

Depending on the date of assessment, the child's expected level was either first or second grade. Grade retention, the need for specific and individualized support in a mainstream school, and inclusion in a special school were considered to represent low academic skills.

Three main domains were assessed for the developmental profile. Motor evaluation was focused on the presence of cerebral palsy (CP). The definition given by the Surveillance for $\mathrm{CP}$ in Europe was used: permanent abnormal tone or decreased strength as a consequence of a nonprogressive early brain insult, and associated with a patent functional deficit. ${ }^{18}$ Motor impairment was further classified with the Gross Motor Function Classification Scale (GMFCS), according to the child's level of gross motor abilities. In the GMFCS schematic, level I subjects walk without limitations, and level V subjects need a manual wheelchair. ${ }^{19}$ The Bimanual Fine Motor Function (BFMF) tool was used to assess the ability to grasp, manipulate, and hold objects for each hand separately (level 0 , no impairment; level 5 , only ability to hold or worse with both hands). ${ }^{20}$

Global intellectual ability was evaluated using the 4 indices of the Wechsler Intelligence Scale for Children-Fourth Edition (WISC-IV): Verbal Comprehension Index (VCI), Perceptual Reasoning Index (PRI), Working Memory Index (WMI), and Processing Speed Index (PSI). Global intellectual deficiency was defined as a full-scale IQ (FSIQ) $<70$. As recommended in WISC-IV Administration and Scoring Manual, when excessive discrepancies between indices precluded the composite FSIQ score validity, only subscores were provided. Global intellectual deficiency was then considered when both VCI and PRI were $<70$.

Finally, the standardized spoken language assessment Nouvelles Epreuves pour l'Examen du Langage was performed. ${ }^{21}$ This battery was validated to test the language profile of 3.5- to 8.5-year-old French-speaking children, including speech and sound abilities as well as expressive and receptive lexicosemantic and morphosyntactic skills. Children with a score $>2$ SD below the mean for 1 of the 4 linguistic components (ie, not including isolated speech and sound delay) were considered to have impaired language.

\section{Biases}

Some families could not be contacted or declined to participate in the present evaluation, and thus the final rate of disabilities could have been misestimated. This incomplete follow-up did not alter the relationship between variables, however, because hypotheses were applied only to those 
who fully completed the current study. One child did not complete the WMI of the WISC-IV, and another 2 children did not complete the PSI. Their VCI and PRI values were used to assess their global intellectual abilities. One child was not assessed for language. Because principal component analysis (PCA) cannot take missing data into consideration, this patient was not included in PCA.

\section{Statistical Analyses}

Descriptive statistics are summarized as percentages of children for each of the 5 variables and as median and IQR for continuous data. PCA was used to evaluate the relationships between variables. In brief, the original data were plotted in a 5-dimensional data space in which each orthogonal axis represented a variable. This space was thereafter projected through the PCA transformation on the plan of maximal contribution, that is, the cross-sectional plan whose axes (the 2 principal components) ensured the best total variance of the dataset. The relative contribution of each variable to these components was graphically represented as a vector. The correlation matrix between each pair of variables was represented by a heat map. Factor analyses were carried out using the $\mathrm{R}$ package FactoMineR. ${ }^{22,23}$ The criteria used for the PCA was the default in FactoMineR.

\section{Results}

Of the 100 patients (Figure 1; available at www.jpeds.com), 2 died in the neonatal period, and 13 families were lost to follow-up. Of the 85 families contacted for the 7-year assessment, 5 declined to participate and 73 accepted. Seven other families refused to participate in the encounter but agreed to complete part of the evaluation by phone. In these families, data on epilepsy, schooling, and parental opinions were recorded.

Data were available for 80 families ( $82 \%$ of the survivors). The assessments requiring a face-to-face encounter (motor examination, language assessment, and WISC-IV) were available for 73 children (74\%); of these, 1 child did not complete the language assessment. The median age at evaluation was 7 years, 1 month (IQR, 7 years, 0 month to 7 years, 2 months).

\section{Epilepsy $(\mathbf{n}=\mathbf{8 0})$}

Sixteen children (20\%) experienced at least 1 seizure after the neonatal period, including 3 with seizure with fever at age 11, 15 , and 36 months. One child had a single untreated afebrile focal seizure at age 5 years. Among the 12 children (15\%) with epilepsy, 10 had multiple seizures and 2 had a single focal afebrile seizure before the initiation of antiepileptic treatment. Four children had epileptic spasms (all before 1 year of age), and the remainder had epilepsy with focal seizures (all after 1 year of age). At the time of assessment, 3 children were seizure-free for $>1$ year without treatment. Thus, the prevalence of active epilepsy at 7 years of age was $11 \%$ (Figure 2; available at www.jpeds.com).

\section{Schooling $(n=80)$}

Sixty children attended their ordinary school grade, 2 at a higher grade than expected. Four of these 60 children received individual educational support through a school assistant individually assigned to the child. Ten children were held back by $1(\mathrm{n}=10)$ or $2(\mathrm{n}=1)$ grade levels within the regular school program, and 7 children were attending a special school. Altogether, 22 children (28\%) had low academic skills.

\section{Developmental Profile}

Motor $(\mathbf{n}=\mathbf{7 3})$. Fifty children had a normal examination, and $23(32 \%)$ had unilateral CP. Ten were classified as GMFCS I, and 13 were classified as GMFCS II (ie, walk with limitations). Eight children were classified as BFMF1 (limitations of more advanced fine motor skills in the impaired hand), 12 were classified as BFMF2 (ability to grasp or hold in the impaired hand), and 2 were classified as BFMF3 (no functional ability in the impaired hand). One child had motor symptoms only in the lower limb (BFMF0).

In 4 children, motor status changed between the previous assessment (at ages 2 or 3.5 years) and the current assessment. Two of them have now mild spastic features (GMFC I, BFMF1/2), and the other 2 have predominant dyskinetic features. None of those who had been diagnosed with CP earlier had recovered normal motor functions at age 7 years.

Global Intellectual $(\mathbf{n}=\mathbf{7 3})$. Median overall results were as follows: VCI, 98 (IQR, 83-108); PRI, 94 (IQR, 76-108); WMI, 87 (IQR, 76-100); PSI, 100 (IQR, 83-111). FSIQ was calculated in only 15 children owing to significant discrepancies between indices that precluded a valid calculation in the 58 other children. Three children had an FSIQ $<70$. Among those with a nonvalid total FSIQ calculation, 3 had both a VCI and a PRI $<70$. A total of 6 children (8\%) exhibited global intellectual deficiency (Figure 3; available at www.jpeds.com).

Spoken Language $(\mathbf{n}=\mathbf{7 2})$. Thirty-five children $(49 \%)$ had impaired language. Numbers of left, right, and bilateral lesions were similar between children with impaired vs normal profiles: $24 / 9 / 2$ vs $22 / 12 / 3$, respectively. The morphosyntactic expressive component was most frequently affected. $26 / 35(74 \%)$ children had both expressive and receptive language impairments, and 7 children $(20 \%)$ had isolated expressive deficiency, and 2 children (6\%) had isolated receptive deficiency. Twenty-six children (74\%) had deficiency in at least 2 of the following components: speech and sound abilities, lexicosemantic, or morphosyntactic. Six children $(17 \%)$ had isolated morphosyntactic deficiency and 3 children $(8 \%)$ had isolated lexicosemantic deficiency.

\section{Co-Occurrence $(\mathrm{n}=72)$}

Figure 4 shows a high co-occurrence between all variables. This was confirmed by PCA, showing that all endpoints were positively correlated (Figures 5 and 6; Figure 5; available at www.jpeds.com). The principal component was 


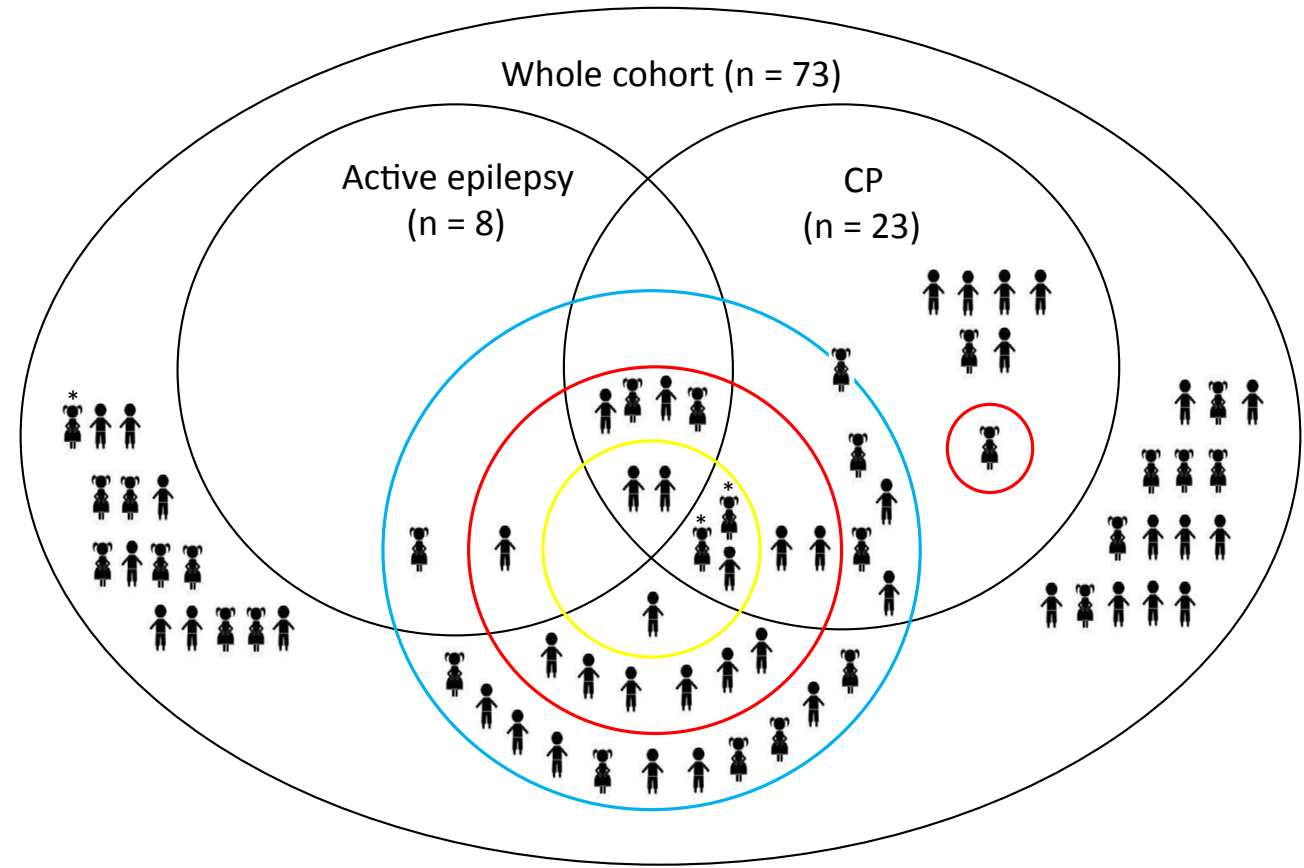

Figure 4. Girls and boys belonging to each of the following categories at 7 years of age: active epilepsy, CP, impaired language (blue circle), low academic skills (red circle), and global intellectual deficiency (yellow circle). One girl with CP was not tested for language. An asterisk indicates children who were epileptic earlier but who were seizure-free for $>1$ year without treatment at 7 years.

particularly linked to schooling. The second axis was more prone to characterize clinical assessment, with 2 sets: language/epilepsy and motor/global intellectual. Although these sets of variables are located in opposite quarters, they contribute roughly equally to the academic dimension. Finally, the factorial plan (Figure 5) can be divided into 3 parts: children with (1) good academic skills and no neurologic signs and those with low academic skills; and either (2) impaired language and active epilepsy; or (3) global intellectual deficiency and CP.

\section{Parental Opinion $(n=69)$}

Forty-three children were classified into at least 1 of the following categories: active epilepsy, low academic skills, $\mathrm{CP}$, global intellectual deficiency, and impaired language (Figure 4). Thirty-one parents (42\%) reported sequelae of the child's neonatal event, 38 (52\%) reported no sequelae, and 3 did not answer. In 49 cases, the parental and medical views matched. In 6 cases, the family thought the child had sequelae but the medical team did not, and in 14 cases the opposite was found. In 1 family in which the parents disagreed, the child was medically evaluated with low academic skills and impaired language.

\section{Discussion}

In this cohort of term newborns with NAIS, most children exhibited some sequelae 7 years later; however, severe disability, such as drug-resistant epilepsy, moderate/severe CP
(GMFCS $\geq \mathrm{III}$ or BFMF $\geq 3$ ), or global intellectual deficiency, is the exception: $6 \%, 3 \%$, and $8 \%$, respectively, with a major co-occurrence. In other words-and to answer to a common question of parents-all were able to walk independently and to talk. These results are in line with previously reported data, but our study has the advantage of longitudinally addressing multimodal outcomes of a large homogeneous population, thereby providing a more comprehensive view of the consequences of NAIS by school age.

Although early imaging determinants of motor outcome after NAIS are now well-accepted, ${ }^{1,16}$ evidence concerning epilepsy is more controversial. Recent longitudinal studies of term and near-term NAIS populations have provided consistent data. 2,9,24 The risk of epilepsy is lower than initially presumed: $9 \%$ at 2 years of age in the Swiss Neuropaediatric Stroke Registry $(\mathrm{n}=74),{ }^{2} 13 \%$ at 2.5 years of age in a US cohort $(\mathrm{n}=46),{ }^{9} 15 \%$ at 7 years of age in our cohort $(\mathrm{n}=80)$, and $15 \%$ at 8.5 years of age in an Italian cohort $(n=55) .{ }^{24}$ Because epilepsy is not necessarily permanent, the prevalence of active epilepsy in any given period is lower than this cumulative incidence over time. Furthermore, epilepsy segregates with impaired development.

The proportion of global intellectual deficiency after NAIS appears to be low. Our $8 \%$ rate is in line with the $11 \%$ rate reported by Ricci et $\mathrm{al}^{25}$ and the $7 \%$ rate reported by Westmacott et $\mathrm{al}^{26}$ in their NAIS population assessed at ages 5.8 years $(\mathrm{n}=28)$ and 9.6 years $(\mathrm{n}=26)$, respectively. Reported results are inconsistent regarding whether these cognitive abilities are maintained at the same level over the course of development, ${ }^{6}$ 


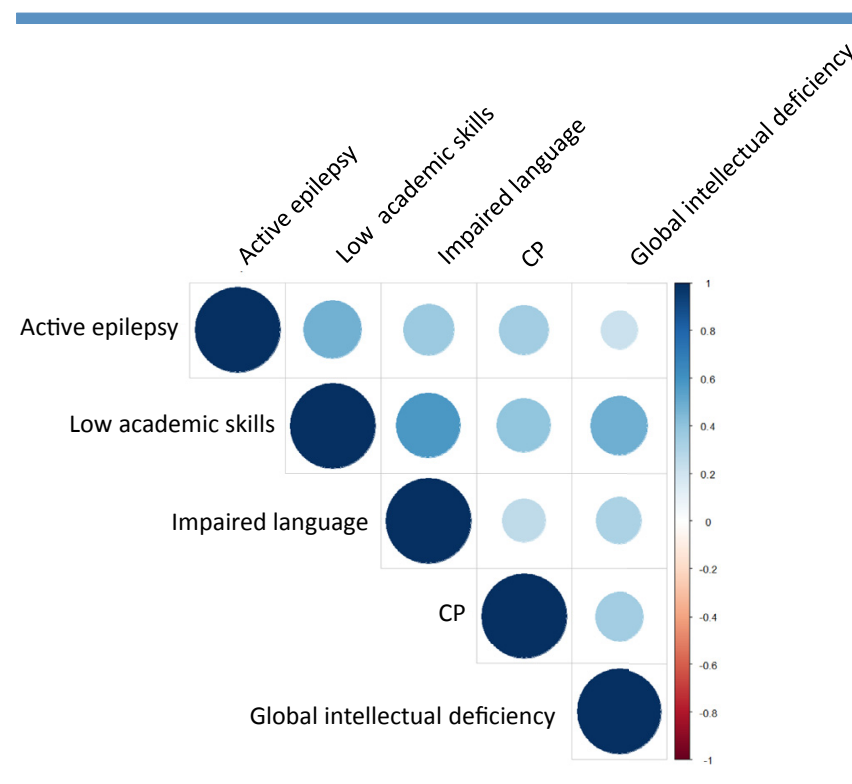

Figure 6. Heat map obtained with PCA of the 5 variables. The color of the circles indicates the direction (blue, positive) of the correlation, and the diameter of the circles indicates its strength.

or whether the children are at increased risk for emerging deficits during school years, notably in nonverbal reasoning. ${ }^{7,26}$

Nonetheless, global intellectual abilities within normal limits do not preclude impaired development. This is particularly apparent in our population, in which $28 \%$ of children have low academic skills after 1 year of mandatory schooling. That this rate will rise steadily as grade level increases is a logical assumption. Even without IQ deficit and behavioral problems, perinatal/childhood stroke impairs social adjustment and participation, with consequences extending to a large range of life skills. ${ }^{27}$

We found a higher prevalence of language impairment than previous reports suggesting that early expressive delays are usually resolved by school age, and that verbal abilities seem to be preserved after early brain insult. ${ }^{11}$ In our cohort as well, VCIs are better maintained than PRIs (Figure 3). Yet, using assessments tools that probe detailed linguistic functions, subtle deficiencies become more apparent; for example, 29 children with PIS who were administered the Clinical Evaluation of Language Fundamentals-Revised at 10.5 years of age had a mean receptive score of 82 , a mean expressive score of 78, and a mean total score of 79 (out of a theorical mean 100), and a mean verbal IQ of 99.6 Specific tests after perinatal/childhood stroke also have revealed that standard skills are preserved, but there is a reduction in more sophisticated language. ${ }^{28,29}$

Ultimately, all of these impairments may weaken schooling. This is particularly salient in our population, in which low academic skill is a subset of impaired language (Figure 4). The co-occurrence between impaired developmental issues and epilepsy is well documented. ${ }^{2,5-12,24}$ This is a prominent point in our cohort as well. Furthermore, all of these issues have been independently associated with low reported health status. ${ }^{30}$ The strongest correlations were observed among schooling, language, and global intellectual abilities (Figure 4). These assessments may represent different approaches of the same field of intellectual dysfunctioning, and CP and epilepsy might be understood as associated or explicative medical variables of this aforementioned field of impairment (Figures 4-6).

It is often hypothesized that the larger the stroke lesion, the more diffuse the impact. Nevertheless, our imaging data at 7 years of age in the same population demonstrate that motor outcome is more strongly related to the localization of the ischemic insult along the motor pathway than to its size. ${ }^{19}$ Impaired development due to motor deficiency itself is an additional, nonexclusive possibility. In a recent study of a large population of children with $\mathrm{CP}$, the most reliable predictor of FSIQ was motor ability, and the second most common independent variable was epilepsy. ${ }^{31}$ Thus, pervasive interactions between motor and other intellectual skills, which occur in normally developing children, ${ }^{32}$ also might arise after early brain insult. The detrimental effect of epilepsy, its treatment, and its socio-familial burden on neuroplasticity and development will also benefit from further research.

The non-population-based design of the AVCnn cohort is a limitation. However, the great majority of participating units (which epitomize the range of neonatal units in France) declared that they had reported consecutively all cases satisfying the inclusion criteria. ${ }^{14}$ According to more recent epidemiologic data, our cohort includes one-third of NAIS cases born during the inclusion period. ${ }^{2}$ Furthermore, the neonatal clinical and imaging data were similar to those reported for other large hospitalized- or population-based studies. ${ }^{2,33,34}$ Thus, the AVCnn cohort likely provides a good representation of NAIS.

Health practitioner-centered and familial perceptions certainly merit further study, given the remaining gaps between parental and medical approaches. The impact of a child's longstanding impairment on the family's day-today life and how parents adapt and cope with the child's diagnosis are increasingly recognized as determinants of well-being and developmental and behavioral trajectories. Understanding these issues and improving familycentered care may serve to identify those who may benefit from specific guidance. A rapidly applied scale to assess the familial impact of perinatal stroke has recently been proposed. ${ }^{35}$ This measure could have been relevant, but was not available at the time the 7 -year assessment study was designed.

In conclusion, this report provides a cross-sectional snapshot at school age of a population of term-born children who sustained an NAIS. Furthermore, the AVCnn cohort is a unique tool providing a research opportunity and methodology to increase our knowledge of developmental issues following stroke in childhood. ${ }^{36}$ The next steps will be dedicated to the early intrinsic (obstetrical characteristics, sex, lesion volume, and laterality) or extrinsic (sociodemographic variables) determinants 
of outcome. This longitudinal approach will help clinicians predict and prevent adverse outcomes.

We are grateful to Laura Valles-Dordal and Marion Guillemin for their help in evaluating language and global intellectual functioning of some of the children in this study. We also thank Stephanie Garcia-Tarodo for her editing assistance.

\section{References}

1. Kirton A, deVeber G. Paediatric stroke: pressing issues and promising directions. Lancet Neurol 2015;14:92-102.

2. Grunt S, Mazenauer L, Buerki SE, Boltshauser E, Mori AC, Datta AN, et al. Incidence and outcomes of symptomatic neonatal arterial ischemic stroke. Pediatrics 2015;135:e1220-8.

3. Raju TN, Nelson KB, Ferriero D, Lynch JK. Ischemic perinatal stroke: summary of a workshop sponsored by the National Institute of Child Health and Human Development and the National Institute of Neurological Disorders and Stroke. Pediatrics 2007;120:609-16.

4. Shusterman M. Introducing the term "early developmental brain injury/ interference" and a new framework for discussing cerebral palsy. Dev Med Child Neurol 2015;57:110-1.

5. Golomb MR, Saha C, Garg BP, Azzouz F, Williams LS. Association of cerebral palsy with other disabilities in children with perinatal arterial ischemic stroke. Pediatr Neurol 2007;37:245-9.

6. Ballantyne AO, Spilkin AM, Hesselink J, Trauner DA. Plasticity in the developing brain: intellectual, language and academic functions in children with ischaemic perinatal stroke. Brain 2008;131:2975-85.

7. Gonzalez-Monge S, Boudia B, Ritz A, Abbas-Chorfa F, Rabilloud M, Iwaz J, et al. A 7-year longitudinal follow-up of intellectual development in children with congenital hemiplegia. Dev Med Child Neurol 2009;51:959-67.

8. Wanigasinghe J, Reid SM, Mackay MT, Reddihough DS, Harvey AS, Freeman JL. Epilepsy in hemiplegic cerebral palsy due to perinatal arterial ischaemic stroke. Dev Med Child Neurol 2010;52:1021-7.

9. Wusthoff CJ, Kessler SK, Vossough A, Ichord R, Zelonis S, Halperin A, et al. Risk of later seizure after perinatal arterial ischemic stroke: a prospective cohort study. Pediatrics 2011;127:e1550-7.

10. van Buuren LM, van der Aa NE, Dekker HC, Vermeulen RJ, van Nieuwenhuizen O, van Schooneveld MM, et al. Cognitive outcome in childhood after unilateral perinatal brain injury. Dev Med Child Neurol 2013;55:934-40.

11. Murias K, Brooks B, Kirton A, Iaria G. A review of cognitive outcomes in children following perinatal stroke. Dev Neuropsychol 2014;39:131-57.

12. Pappas A, Shankaran S, McDonald SA, Vohr BR, Hintz SR, Ehrenkranz RA, et al. Cognitive outcomes after neonatal encephalopathy. Pediatrics 2015;135:e624-34.

13. Vandenbroucke JP, von Elm E, Altman DG, Gøtzsche PC, Mulrow CD, Pocock SJ, et al. Strengthening the Reporting of Observational Studies in Epidemiology (STROBE): explanation and elaboration. Int J Surg 2014; 12:1500-24.

14. Chabrier S, Saliba E, Nguyen The Tich S, Charollais A, Varlet MN, Tardy B, et al. Obstetrical and neonatal characteristics vary with birthweight in a cohort of 100 term newborns with symptomatic arterial ischemic stroke. Eur J Paediatr Neurol 2010;14:206-13.

15. Darteyre S, Renaud C, Vuillerot C, Presles E, Kossorotoff M, Dinomais M, et al. Quality of life and functional outcome in early school-aged children after neonatal stroke: a prospective cohort study. Eur J Paediatr Neurol 2014;18:347-53.
16. Husson B, Hertz-Pannier L, Renaud C, Allard D, Presles E, Landrieu P, et al. Motor outcomes after neonatal arterial ischemic stroke related to early MRI data in a prospective study. Pediatrics 2010;126:912-8. Erratum: Pediatrics 2010;126:1053.

17. Berg AT, Berkovic SF, Brodie MJ, Buchhalter J, Cross JH, van Emde Boas W, et al. Revised terminology and concepts for organization of seizures and epilepsies: report of the ILAE Commission on Classification and Terminology, 2005-2009. Epilepsia 2010;51:676-85.

18. Surveillance of Cerebral Palsy in Europe (SCPE). Surveillance of cerebral palsy in Europe: a collaboration of cerebral palsy surveys and registers. Dev Med Child Neurol 2000;42:816-24.

19. Dinomais M, Hertz-Pannier L, Groeschel S, Chabrier S, Delion M, Husson B, et al. Long-term motor function after neonatal stroke: lesion localization above all. Hum Brain Mapp 2015;36:4793-807.

20. Elvrum AK, Andersen GL, Himmelmann K, Beckung E, Öhrvall AM, Lydersen S, et al. Bimanual fine motor function (BFMF) classification in children with cerebral palsy: aspects of construct and content validity. Phys Occup Ther Pediatr 2016;36:1-16.

21. Chevrie Muller C, Plaza M. N-EEL: Nouvelles Epreuves pour l'Examen du Langage. Bayeux: ECPA Editions; 2001 (in French).

22. Husson F, Josse J, Lê S, Mazet J. FactoMineR: Factor analysis and data mining with R. R package version 1.04 (2007). http://cran.R-project. org/package $=$ FactoMineR. Accessed October 30, 2015.

23. R Development Core Team. R: A language and environment for statistical computing. http://www.R-project.org. Accessed October 30, 2015.

24. Suppiej A, Mastrangelo M, Mastella L, Accorsi P, Grazian L, Casara G, et al. Pediatric epilepsy following neonatal seizures symptomatic of stroke. Brain Dev 2016;38:27-31.

25. Ricci D, Mercuri E, Barnett A, Rathbone R, Cota F, Haataja L, et al. Cognitive outcome at early school age in term-born children with perinatally acquired middle cerebral artery territory infarction. Stroke 2008; 39:403-10.

26. Westmacott R, MacGregor D, Askalan R, deVeber G. Late emergence of cognitive deficits after unilateral neonatal stroke. Stroke 2009;40:2012-9.

27. Lo W, Gordon A, Hajek C, Gomes A, Greenham M, Perkins E, et al. Social competence following neonatal and childhood stroke. Int J Stroke 2014;9:1037-44.

28. Chapman SB, Max JE, Gamino JF, McGlothlin JH, Cliff SN. Discourse plasticity in children after stroke: age at injury and lesion effects. Pediatr Neurol 2003;29:34-41.

29. Reilly JS, Wasserman S, Appelbaum M. Later language development in narratives in children with perinatal stroke. Dev Sci 2013;16:67-83.

30. Smith SE, Vargas G, Cucchiara AJ, Zelonis SJ, Beslow LA. Hemiparesis and epilepsy are associated with worse reported health status following unilateral stroke in children. Pediatr Neurol 2015;52:428-34.

31. Gabis LV, Tsubary NM, Leon O, Ashkenasi A, Shefer S. Assessment of abilities and comorbidities in children with cerebral palsy. J Child Neurol 2015;30:1640-5.

32. van der Fels IM, Te Wierike SC, Hartman E, Elferink-Gemser MT, Smith J, Visscher C. The relationship between motor skills and cognitive skills in 4-16 year old typically developing children: a systematic review. J Sci Med Sport 2015;18:697-703.

33. Kurnik K, Kosch A, Sträter R, Schobess R, Heller C, Nowak-Göttl U. Recurrent thromboembolism in infants and children suffering from symptomatic neonatal arterial stroke: a prospective follow-up study. Stroke 2003;34:2887-92.

34. Kirton A, Armstrong-Wells J, Chang T, Deveber G, Rivkin MJ, Hernandez M, et al. Symptomatic neonatal arterial ischemic stroke: the International Pediatric Stroke Study. Pediatrics 2011;128:e1402-10.

35. Bemister TB, Brooks BL, Kirton A. Development, reliability, and validity of the Alberta Perinatal Stroke Project Parental Outcome Measure. Pediatr Neurol 2014;51:43-52.

36. Fuentes A, Deotto A, Desrocher M, deVeber G, Westmacott R. Determinants of cognitive outcomes of perinatal and childhood stroke: a review. Child Neuropsychol 2016;22:1-38. 
Additional members of the AVCnn Study Group include:

University of Saint-Étienne, Saint-Étienne, France: Stéphane Darteyre, MD, and Céline Dégano, MSc; Centre Hospitalier Universitaire \& University of Angers, Angers, France: Matthieu Delion MD, PhD; University of Tübingen, Tübingen, Germany: Samuel Groeschel, MD; Unité mixte de recherche Institut national de la santé et de la recherche médicale U1129 \& Neurospin Commissariat à l'énergie atomique et aux énergies alternatives -Saclay, Gif-sur-Yvette, France: Lucie Hertz-Pannier, MD, PhD; Assistance publiqueHôpitaux de Paris Bicêtre Hospital, Paris, France: Béatrice Husson, MD; Centre Hospitalier Universitaire \& University of Saint-Étienne, Saint-Étienne, France: Emilie Presles MSc; Centre Hospitalier Universitaire Bordeaux France; Magaly Ravel, MD; Hospices Civils de Lyon \& University of Lyon1, Lyon France: Carole Vuillerot, MD, PhD. 


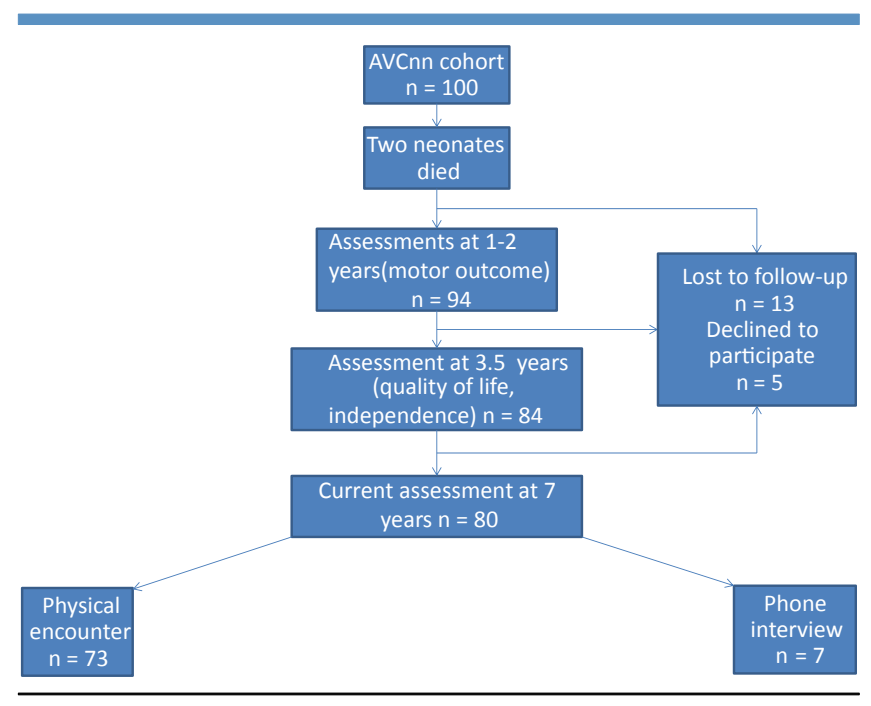

Figure 1. Follow-up until the age of 7 years of a cohort of 100 children with an NAIS.

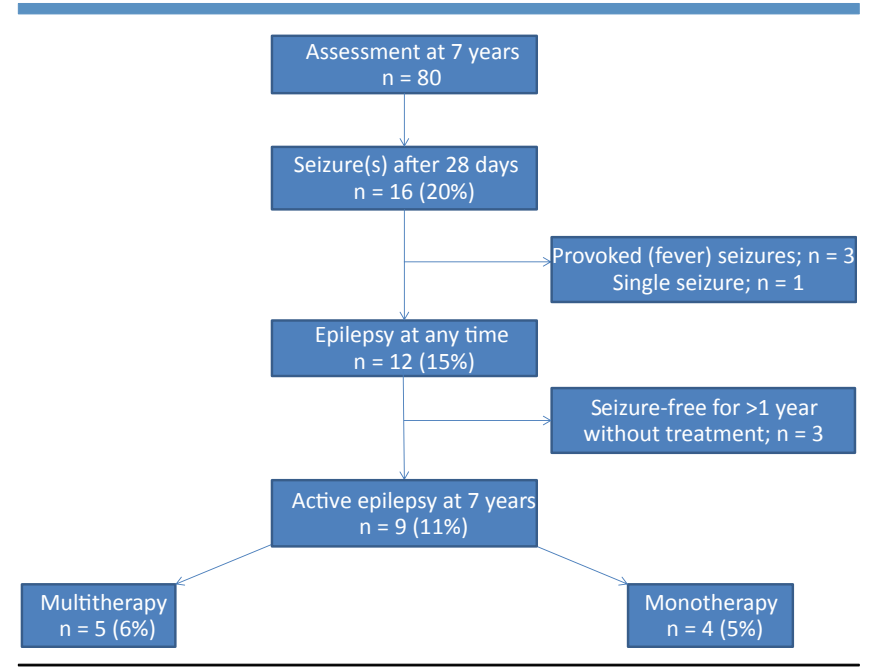

Figure 2. Seizures and epilepsy from ages 29 days to 7 years in 80 children with an NAIS. 

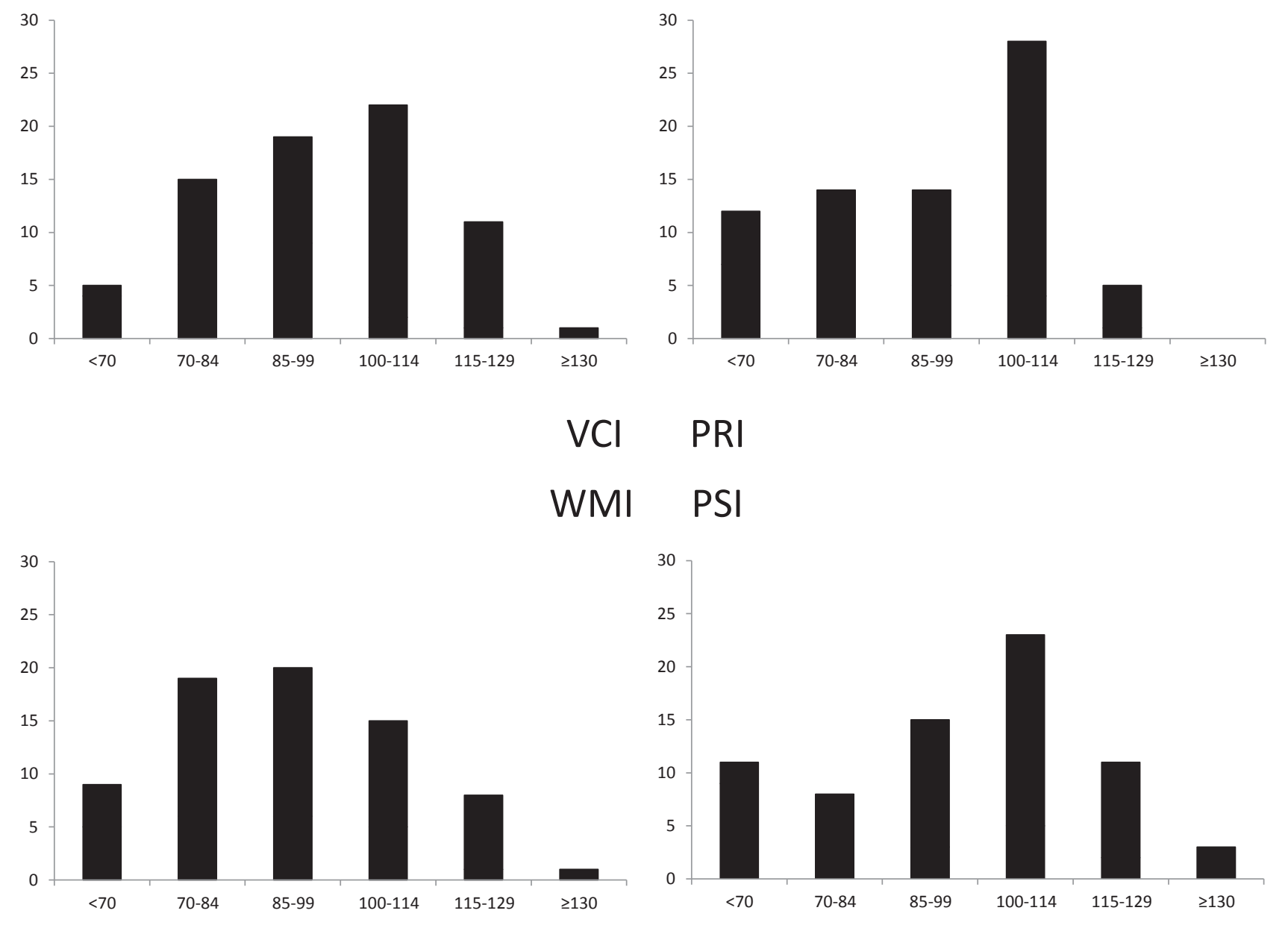

Figure 3. Overall results of the 4 indices of the WISC-IV at 7 years of age. $\mathrm{VCl}$ and PRI were assessed in all children $(n=73)$. WMI was assessed in 72 children; PSI, in 71 children.

\section{Variables factor map (PCA)}

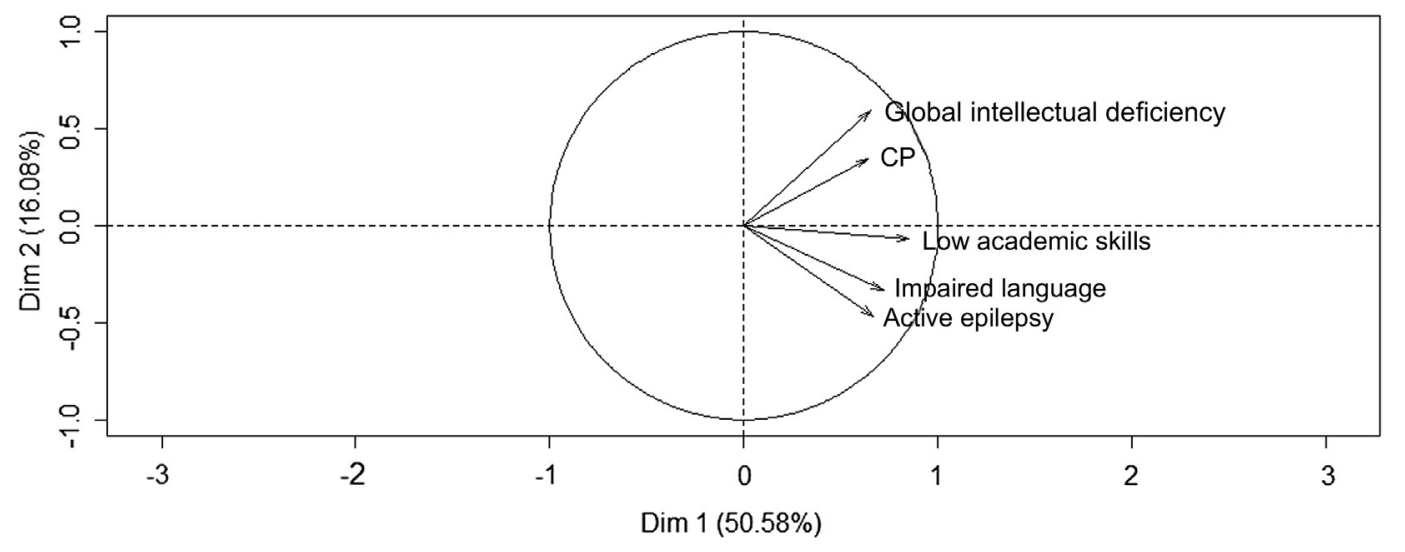

Figure 5. Variable factorial plan obtained with PCA of the 5 variables. All vectors contribute positively to the principal axis. The value of the analysis is strengthened by the fact that the 2 principal dimensions represent two-thirds of the total variance of the dataset, and that all vectors are close to the circle of equilibrium contribution. 